\title{
1 Leaf wax composition and carbon isotopes vary among major conifer groups
}

3 Aaron F. Diefendorf ${ }^{a^{*}}$, Andrew B. Leslie ${ }^{b}$, and Scott L. Wing ${ }^{c}$

$4 \quad{ }^{a}$ Department of Geology, University of Cincinnati, Cincinnati, OH, 45221 USA

$5 \quad{ }^{\mathrm{b}}$ Department of Ecology and Evolutionary Biology, Brown University, Providence, RI 02912 USA

$6 \quad{ }^{\mathrm{c}}$ Department of Paleobiology, Smithsonian Institution, Washington, DC 20013 USA

$7 \quad$ *Corresponding Author. Tel. : +1-513-556-3787.

8 E-mail address: aaron.diefendorf@uc.edu (A.F. Diefendorf).

11 Keywords: plant biomarkers, $n$-alkanes, compound specific isotope analyses, conifer phylogeny 
14 Leaf waxes (e.g. $n$-alkanes, $n$-alkanoic acids) and their carbon isotopes $\left(\delta^{13} \mathrm{C}\right)$ are commonly used to track 15 past changes in the carbon cycle, water availability, and plant ecophysiology. Previous studies indicated 16 that conifers have lower $n$-alkane concentrations than angiosperms and that ${ }^{13} \mathrm{C}$ fractionation during $n$ 17 alkane synthesis $\left(\varepsilon_{n \text {-alkane }}\right)$ is smaller than in angiosperms. These prior studies, however, sampled a limited phylogenetic and geographic subset of conifers, leaving out many important subtropical and Southern

19 Hemisphere groups that were once widespread and common components of fossil assemblages. To expand on previous work, we collected 43 conifer species (and Ginkgo biloba) from the University of

21 California Botanical Garden at Berkeley, sampling all extant conifer families and almost two-thirds of extant genera. We find that Pinaceae, including many North American species used in previous studies,

23 have very low or no $n$-alkanes. However, other conifer groups have significant concentrations of $n$ -

24 alkanes, especially Southern Hemisphere Araucariaceae and Podocarpaceae (monkey puzzles, Norfolk 25 Island pines, and yellowwoods), and many species of Cupressaceae (junipers and relatives). Within the 26 Cupressaceae, we find total $n$-alkane concentrations are high in subfamilies Cupressoideae and

27 Callitroideae, but significantly lower in the early diverging taxodioid lineages (including bald cypress and 28 redwood). Individual $n$-alkane chain lengths have a weak phylogenetic signal, except for $n$-C $\mathrm{C}_{29}$ alkane, but 29 when combined using average chain length (ACL), a strong phylogenetic signal emerges. The strong 30 phylogenetic signal in ACL, observed in the context of a common growth environment for all plants we 31 sampled, suggests that ACL is strongly influenced by factors other than climate. An analysis of $\varepsilon_{n \text {-alkane }}$ 32 indicates a strong phylogenetic signal in which the smallest biosynthetic fractionation occurs in Pinaceae 33 and the largest in Taxaceae (yews and relatives). The relationship between phylogeny and $\varepsilon_{n \text {-alkane }}$ may be 34 related to differences in carbon metabolism among conifer clades. These results have important 35 implications for interpreting $n$-alkane $\delta^{13} \mathrm{C}$ values in sedimentary archives, especially outside of North 36 America. 


\section{INTRODUCTION}

The leaf waxes of vascular plants are primarily composed of long-chain $n$-alkyl compounds including the $n$-alkanes, $n$-alkanoic acids, and $n$-alkanols (Eglinton et al., 1962; Eglinton and Hamilton, 1967;

41 Kolattukudy et al., 1976). These leaf waxes are widely used to reconstruct environmental change because they are commonly transported and preserved in sediments from which they are easily extracted and analyzed (Cranwell, 1981; Rieley et al., 1991; Collister et al., 1994a; Freeman and Colarusso, 2001). Of

44 the leaf waxes, $n$-alkanes have been the focus of most geologic studies, although other waxes, such as $n$ 45 alkanoic acids and $n$-alkanols, can be informative when preserved (Feakins et al., 2007; Douglas et al., 2012; Sachse et al., 2012). Leaf waxes, especially $n$-alkanes, have been applied to answer various paleoecological questions, such as distinguishing relative changes in paleotemperature or paleohydrology (Castañeda and Schouten, 2011; Freeman and Pancost, 2014; Bush and McInerney, 2015). More recently, analyses of the carbon and hydrogen isotope composition of leaf waxes has greatly expanded their utility for paleoclimate studies, and they have been used extensively to characterize past changes in the carbon cycle, water availability, hydrology, and vegetation (e.g., Pagani et al., 2006; Schouten et al., 2007; Smith et al., 2007; Tierney et al., 2008; Castañeda et al., 2009; Tipple et al., 2011; Niedermeyer et al., 2014).

Despite the widespread use of leaf waxes, many unanswered questions about them remain. For example, the variation in wax concentration and composition among and within many major plant groups has not been quantified and is largely unknown (Diefendorf et al., 2011; Bush and McInerney, 2013). Plant traits

57 such as leaf lifespan, cuticle thickness, and specific leaf area may influence composition of short-chain $n$ alkanoic acids (Mueller et al., 2012), but their influence on the composition of other waxes is largely unstudied.. Climate may also influence leaf wax composition, as observed in studies of $n$-alkane average chain length, but relationships with climate tend to be weak and to vary by species (e.g., Dodd and

61 Poveda, 2003; Sachse et al., 2006; Shepherd and Wynne Griffiths, 2006; Castañeda et al., 2009; Vogts et 62 al., 2012; Hoffmann et al., 2013; Tipple and Pagani, 2013; Bush and McInerney, 2015). In addition, the 
timing of leaf wax synthesis may vary among species, which has important consequences for interpreting

64 isotope signals preserved in these waxes (Sachse et al., 2006; Sachse et al., 2009; Tipple et al., 2013).

65 Taken together, these unanswered questions complicate interpretations of leaf waxes found in sediments,

66 especially if plant community composition has changed in combination with climate.

In this study, we focus on understanding variation in $n$-alkane composition among conifers, a major nonangiosperm seed plant group with a long and abundant fossil record. Conifers dominate many high elevation and high latitude ecosystems in the modern world, especially in the Northern Hemisphere, but the group has a global distribution and also includes many tropical members. Prior studies have suggested that conifers differ from angiosperms in their $n$-alkane chemistry, for example, having $n$-alkane concentrations 200 times lower when grown under the same climatic conditions (Diefendorf et al., 2011; Bush and McInerney, 2013). Also, ${ }^{13} \mathrm{C}$ fractionation during $n$-alkane biosynthesis $\left(\varepsilon_{\text {lipid }}\right)$ is $\sim 2 \%$ less than in angiosperms, suggesting underlying differences in the allocation of carbon to different materials (e.g., carbohydrates, amino acids, lipids) among major plant groups (e.g. Diefendorf et al., 2011). However, Diefendorf et al. (2011) measured only a few Northern Hemisphere conifer species. Many important subtropical, tropical, and Southern Hemisphere conifers groups have been ignored, even though they were more widespread in the past and are common components of fossil assemblages.

81 To expand on previous studies, we collected 43 conifer species (and Ginkgo biloba) from the University of California Botanical Garden at Berkeley. The sample includes species from all extant conifer families and more than $60 \%$ of extant genera. By collecting all specimens at a common site we attempted to

84 minimize the confounding effects of climate, allowing potential phylogenetic patterns in the $\delta^{13} \mathrm{C}$ of leaf 85 waxes to be expressed more strongly. We find that species belonging to different major conifer lineages 86 have different $n$-alkane compositions and concentrations even when grown in the same climate. A strong 87 phylogenetic signal is also apparent in $n$-alkane isotope fractionation values. These results have important 
consequences for interpreting sedimentary leaf waxes where conifers are or were part of the plant community

\section{MATERIALS AND METHODS}

\subsection{Sampling location and leaf collection}

Fresh leaf tissue was collected from 43 conifer species and from Ginkgo biloba at the University of California Botanical Garden at Berkeley (UCBGB; $37.8752^{\circ} \mathrm{N}, 122.2386^{\circ} \mathrm{W}, 210 \mathrm{~m}$ ) in December of 2011. Evergreen leaf tissue was sampled from the 2011 leaf flush. The total rainfall for 2011 was $602 \mathrm{~mm}$ and the average minimum and maximum temperatures are 8.8 and $18.3^{\circ} \mathrm{C}$, respectively (PRISM, 2014). For each species, leaf tissue was collected from multiple branches on the sun-exposed side of a single mature tree per species using scissors, pruners, or pole-pruners. Sampling height ranged from 2 to $3 \mathrm{~m}$ except for Sequoiadendron giganteum and Sequoia sempervirens, which were sampled at $\sim 25 \mathrm{~m}$. The canopy structure at the UCBGB is very open and therefore it is unlikely that soil respiration generates a

${ }^{13} \mathrm{C}$-depeleted $\mathrm{CO}_{2}$ layer at this sampling height. Sample collection information is reported in electronic annex Table EA-1. Samples ( $10 \mathrm{~g})$ were gently rinsed with deionized water, frozen $\left(-20^{\circ} \mathrm{C}\right)$, freezedried, and homogenized by powdering with a ball mill.

\subsection{Lipid extraction and separation}

Powdered leaves were extracted using an accelerated solvent extractor (Dionex ASE 350) with 2:1 (v/v) $\mathrm{DCM} / \mathrm{MeOH}$ with three extraction cycles at $10.34 \mathrm{MPa}(1400 \mathrm{psi})$ and $100^{\circ} \mathrm{C}$. The total lipid extract (TLE) was base saponified to cleave ester groups with $2.5 \mathrm{ml} 0.5 \mathrm{~N} \mathrm{KOH}$ in 3:1 (v/v) MeOH/water) for 2 $\mathrm{h}$ at $75^{\circ} \mathrm{C}$. After cooling, $2 \mathrm{ml}$ of $\mathrm{NaCl}$ in water $(5 \%$, w/w) was added and then the solution was acidified 
113 with $6 \mathrm{~N} \mathrm{HCl}$ to a $\mathrm{pH}$ of 1 . The acidic solution was extracted with hexanes/DCM (4:1, v/v), neutralized

114 with $\mathrm{NaHCO}_{3} / \mathrm{H}_{2} \mathrm{O}\left(5 \%\right.$, w/w), followed by water removal over $\mathrm{Na}_{2} \mathrm{SO}_{4}$.

116 The saponified lipid extract was subsequently separated into four polarity fractions following a modified

117 version of Sessions (2006). Briefly, $0.5 \mathrm{~g}$ of aminopropyl-bonded silica gel (Sigma Aldrich, St. Louis,

118 USA) was loaded into $6 \mathrm{ml}$ SPE glass tubes with PTFE frits on a Visiprep SPE vacuum manifold with

119 disposable PTFE liners (Sigma Aldrich). Hydrocarbons were eluted with $4 \mathrm{ml}$ of hexanes, ketones eluted

120 with $8 \mathrm{ml}$ of hexanes/DCM (6:1, v/v), alcohols eluted with $8 \mathrm{ml}$ of DCM/acetone (9:1, v/v), and acids

121 eluted with $8 \mathrm{ml}$ of DCM/formic acid (49:1, v/v).

122

\subsection{Identification and quantification}

Lipids were identified and quantified with a gas chromatograph (GC)-mass selective detector (MSD) and flame ionization detector (FID). An Agilent 7890A GC with multi mode inlet operated in pulsed splitless mode at $320^{\circ} \mathrm{C}$ was interfaced to an Agilent $5975 \mathrm{C}$ quadrupole mass selective detector with an electron-

128 impact ionization of $70 \mathrm{eV}$. Compounds were separated on a fused silica capillary column (Agilent J\&W 129 DB-5ms; $30 \mathrm{~m}, 0.25 \mathrm{~mm}, 25 \mu \mathrm{m}$ ) with a $5 \mathrm{~m}$ guard column (Restek Rxi, $5 \mathrm{~m}, 0.32 \mathrm{~mm}$ ) and a carrier gas 130 (helium) flow of $1.5 \mathrm{ml} / \mathrm{min}$. For hydrocarbons, the oven program was as follows: $60^{\circ} \mathrm{C}$ for $1 \mathrm{~min}$, 131 followed by a ramp $\left(6^{\circ} \mathrm{C} / \mathrm{min}\right)$ to $320^{\circ} \mathrm{C}$ and held for 15 minutes. For all other fractions, the oven 132 program was as follows: $60^{\circ} \mathrm{C}$ for $1 \mathrm{~min}$, followed by a ramp $\left(20^{\circ} \mathrm{C} / \mathrm{min}\right)$ to $130^{\circ} \mathrm{C}$, then a ramp $\left(4^{\circ} \mathrm{C}\right)$ to $133 \quad 320^{\circ} \mathrm{C}$ and held for 10 min. Following GC separation, column effluent was split (1:1) between the FID 134 and MSD with a 2-way splitter with He makeup to keep pressure constant at $182 \mathrm{~Pa}$. The MSD scanned a 135 mass range of $\mathrm{m} / \mathrm{z} 45-800$ at 2 scans per second. Compounds were identified with authentic standards, 136 library databases (NIST 2008 and Wiley 2009), published spectra, spectral interpretation, and retention 137 times. 
139 For quantification by FID, hydrocarbons were dissolved quantitatively in hexanes spiked with $10 \mu \mathrm{g} / \mathrm{ml}$

140 1-1'-binapthyl as the internal standard. For the alcohol and acid fractions, aliquots of the saponified lipid 141 extract were dissolved in pyridine spiked with $20 \mu \mathrm{g} / \mathrm{ml}$ of 2-dodecanol, phthalic acid, and undecanoic

142 acid, as the internal standards, and derivatized with $N, O$-bis(trimethylsilyl)trifluoroacetamide (BSTFA;

143 Sigma Aldrich) at $70{ }^{\circ} \mathrm{C}$ for $15 \mathrm{~min}$. Compound peak areas were normalized to the internal standard and

144 converted to concentrations using external standard response curves. For hydrocarbons, the external

145 standard was $\mathrm{C}_{7}$ to $\mathrm{C}_{40} n$-alkanes (Sigma Aldrich) and for $n$-alkanols and $n$-alkanoic acids, the external

146 standard was a mix of even $n$-alkanols and $n$-alkanoic acids. To determine precision and accuracy,

147 additional analyses were made of standards treated as samples. For the $n$-alkanes, a mixture of $\mathrm{C}_{22}$ to $\mathrm{C}_{38}$

148 at $10.00 \mu \mathrm{g} / \mathrm{ml}$ was measured $(\mathrm{n}=5)$ with a mean precision of $0.09 \mu \mathrm{g} / \mathrm{ml}(1 \sigma)$ and a mean accuracy of

$1490.71 \mu \mathrm{g} / \mathrm{ml}$. For the polar compounds, a mixture of $n$-alkanols and $n$-alkanoic acids at $25.00 \mu \mathrm{g} / \mathrm{ml}$ was

150 measured $(\mathrm{n}=11)$ with a mean precision of $3.37 \mu \mathrm{g} / \mathrm{ml}(1 \sigma)$ and a mean accuracy of $2.40 \mu \mathrm{g} / \mathrm{ml}$.

151 Compound concentrations were normalized to the dry leaf mass $(\mu \mathrm{g} / \mathrm{g})$.

153 To characterize changes in long chain $n$-alkane lengths, we calculated average chain length (ACL) values 154 using the equation of Eglinton and Hamilton (1967):

$$
\mathrm{ACL}=\frac{25 n-\mathrm{C}_{25}+27 n-\mathrm{C}_{27}+29 n-\mathrm{C}_{29}+31 n-\mathrm{C}_{31}+33 n-\mathrm{C}_{33}+35 n-\mathrm{C}_{35}+37 n-\mathrm{C}_{37}}{n-\mathrm{C}_{25}+n-\mathrm{C}_{27}+n-\mathrm{C}_{29}+n-\mathrm{C}_{31}+n-\mathrm{C}_{33}+n-\mathrm{C}_{35}+n-\mathrm{C}_{37}}
$$

where $n$-alkane concentrations are converted to chain length numbers. To characterize differences in odd

157 chain length preference, the carbon preference index (CPI) was measured using the Marzi et al. (1993)

158 equation:

$$
\mathrm{CPI}=\frac{\left(n-\mathrm{C}_{23}+n-\mathrm{C}_{25}+n-\mathrm{C}_{27}+n-\mathrm{C}_{29}+n-\mathrm{C}_{31}+n-\mathrm{C}_{33}+n-\mathrm{C}_{35}\right)+\left(n-\mathrm{C}_{25}+n-\mathrm{C}_{27}+n-\mathrm{C}_{29}+n-\mathrm{C}_{31}+n-\mathrm{C}_{33}+n-\mathrm{C}_{35}+n-\mathrm{C}_{37}\right)}{2 \times\left(n-\mathrm{C}_{24}+n-\mathrm{C}_{26}+n-\mathrm{C}_{28}+n-\mathrm{C}_{30}+n-\mathrm{C}_{32}+n-\mathrm{C}_{34}+n-\mathrm{C}_{36}\right)}
$$

where larger numbers indicated a greater preference for odd chain lengths.

\subsection{Compound-specific carbon isotope analyses}


164 Compound-specific carbon isotope analyses of the $n$-alkanes were determined by GC-combustion (C)-

165 IRMS. Prior to analysis, unsaturated hydrocarbons were removed with $0.5 \mathrm{~g}$ of $5 \% \mathrm{Ag}$-impregnated silica 166 gel (w/w) with $4 \mathrm{ml}$ of hexanes. GC-C-IRMS was performed with a Thermo Trace GC Ultra coupled via 167 an Isolink combustion furnace and Conflo IV open split interfaced to a Thermo Electron Delta V

168 Advantage IRMS. GC conditions were similar to the above with the exception of a faster ramp rate (8

$169{ }^{\circ} \mathrm{C} / \mathrm{min}$ ). Isotopic abundances were determined relative to a reference gas calibrated with Mix A (Arndt 170 Schimmelmann, Indiana University) and sample size dependency (linearity) monitored with Mix B.

171 Carbon isotope values of samples (S) are reported in delta notation relative to the standard Vienna Pee 172 Dee Belemnite (VPDB) as $\delta^{13} \mathrm{C}=\left[\left({ }^{13} \mathrm{R}_{\mathrm{S}} /{ }^{13} \mathrm{R}_{\mathrm{VPDB}}\right)-1\right]$ where ${ }^{13} \mathrm{R}={ }^{13} \mathrm{C} /{ }^{12} \mathrm{C}$. Carbon isotope accuracy was 173 monitored with co-injected $n-\mathrm{C}_{41}$ alkane and the precision and accuracy were $0.03 \%$ o $(1 \sigma ; \mathrm{n}=144)$ and -

$174 \quad 0.17 \%$, respectively, over the course of analysis.

176 Isotope fractionation that occurs during leaf wax synthesis was estimated using $\varepsilon_{\text {lipid }}$ notation (Chikaraishi 177 et al., 2004) with the following equation:

$$
\varepsilon_{n \text {-alkane }}=\left(\frac{\delta^{13} \mathrm{C}_{\text {lipid }}+1000}{\delta^{13} \mathrm{C}_{\text {leaf }}+1000}-1\right) \times 10^{3}
$$

179 with the assumption that $\delta^{13} \mathrm{C}_{\text {leaf }}$ approximates the reactant (pyruvate) utilized to synthesize $n$-alkanes. $\varepsilon_{n-}$ 180 alkane values were calculated for each individual $n$-alkane chain length, concentration permitting, between

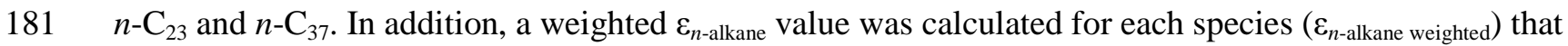
182 takes into account the concentration of each odd $n$-alkane between $n-\mathrm{C}_{25}$ and $n-\mathrm{C}_{37}$ and the $\delta^{13} \mathrm{C}$ value of 183 the respective chain length.

\subsection{Bulk carbon isotope analyses} continuous flow (He; $120 \mathrm{ml} / \mathrm{min}$ ) on a Costech elemental analyzer (EA) interfaced with a Thermo 
189 Electron Delta V Advantage isotope ratio mass spectrometer (IRMS) with a Conflo IV. $\delta^{13} \mathrm{C}$ values were

190 corrected for sample size dependency and normalized to the VPDB scale using a two-point calibration

191 with IAEA calibrated (NBS-19, L-SVEC) in-house standards (from -38.26\%o to -11.35\%o) following

192 Coplen et al. (2006). Error was determined by analyzing additional independent standards with a

193 precision of $0.05 \%$ o $(n=18 ; 1 \sigma)$ and accuracy of $0.04 \%$ o $(n=14)$.

\subsection{Phylogenetic data and statistical analyses}

In order to assess the effect of evolutionary relationships on $n$-alkane patterns, we first grouped conifer species according to major clades as recognized by previous phylogenetic studies (Rai et al., 2008; Leslie et al., 2012). These generally correspond to traditionally recognized conifer families, and include the Araucariaceae, Cupressaceae, Pinaceae, Podocarpaceae, Sciadopityaceae, and Taxaceae. We also analyzed three additional subclades of Cupressaceae: the Cupressoideae (Northern Hemisphere cypresses

202 and junipers), the Callitroideae (Southern Hemisphere cedars), and the taxodioid Cupressaceae, an 203 informal group of early-diverging lineages that includes species such as redwoods and bald cypresses.

In the context of this initial phylogenetic grouping, we used a principal components analysis (PCA) of $n$ performed a phylogenetically corrected PCA, a statistical correction which accounts for the phylogenetic non-independence of the data (Revell, 2009). This method uses a phylogenetic tree and a Brownian

209 motion $(\mathrm{BM})$ model of trait evolution to calculate expected trait covariance simply due to relatedness; that

210 is, closely related species should have similar trait values while more distantly related taxa should have

211 more divergent values. This phylogenetic covariance matrix is then used in the PCA analysis of the

212 correlation matrix of trait values. In essence, the analysis uses the non-phylogenetic residual variation

213 among the taxa to compute eigenvalues and eigenvectors, so that taxa are more appropriately ordinated on 
214 principal component axes (Revell, 2009). Studies suggest this method can reduce error in statistical

215 results, even if the data is subsequently used in further phylogenetic analyses (see Revell, 2009).

217 We next directly tested for phylogenetic signal in these variables ( $n$-alkane concentration, ACL, and CPI),

218 as well as for Principal Components Axis 1 (PC 1) scores (in both traditional PCA and phylogenetically

219 corrected PCA), using the $K$-statistic of Blomberg et al. (2003). Blomberg's $K$ is a measure of how well

220 the distribution of observed trait values follows expectations from a BM process given the phylogenetic

221 relationships among the species. A value of 1.0, for example, indicates that a trait exhibits the distribution

222 expected to occur under a BM process given the phylogenetic tree, while a value much less than 1

223 indicates that it is distributed without respect to observed phylogenetic relationships. We also used the $K$ -

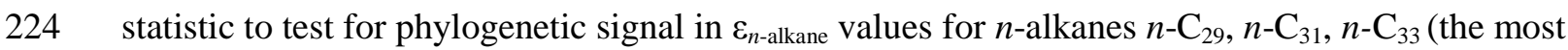

225 common $n$-alkanes measured in sedimentary archives), and for the weighted $\varepsilon_{n \text {-alkane }}$ average for each

226 species.

227

228 All phylogenetic analyses in this study used a time-calibrated molecular conifer phylogeny from Leslie et

229 al. (2012). This tree was subsampled to include only the 43 conifer species used in this analysis. Ginkgo

230 was not included in the (Leslie et al., 2012) study and was therefore excluded from the phylogenetic

231 analyses. The phylogenetically-adjusted PCA and phylogenetic signal tests were performed using the

232 package phytools (Revell, 2012) in the open source statistical software R version 3.1.2 (R core team,

233 2014). Other statistical analyses were preformed using R and JMP Pro 11.0 (SAS, Cary, USA).

\section{RESULTS AND DISCUSSION}

236

\section{1. $n$-Alkanoic acid and $n$-alkanol concentrations among conifers}


The $n$-alkanoic acids (even chains from $\mathrm{C}_{24}$ to $\mathrm{C}_{30}$ ) are the least abundant of the $n$-alkyl lipids, having a mean concentration of $50 \pm 62 \mu \mathrm{g} / \mathrm{g}(1 \sigma, \mathrm{n}=43)$ among all species, although they are not necessarily the

241 least abundant $n$-alkyl lipids in each subfamily (Fig. 1). The $n$-alkanols (even chains from $\mathrm{C}_{24}$ to $\mathrm{C}_{34}$ ) have

242 roughly twice the concentration of the $n$-alkanoic acids when compared among all species $(\bar{X}=99 \pm 252$

$243 \mu \mathrm{g} / \mathrm{g}, 1 \sigma, \mathrm{n}=43$ ), but concentrations are much more variable among subfamilies. Taxodium distichum is

244 unique among all species in having exceptionally high $n$-alkanol concentrations $(1590 \mu \mathrm{g} / \mathrm{g})$. There is no

245 a priori reason to suspect such high concentrations in this species given that the two closely related

246 species, Glyptostrobus pensilis and Cryptomeria japonica, as well as the rest of the Cupressaceae, have

247 low concentrations. Overall, the $n$-alkanoic acid and $n$-alkanol concentrations measured here are similar

248 to previous studies of conifer leaf waxes (Diefendorf et al., 2011).

Total $n$-alkanol concentrations among extant conifer species do not show significant phylogenetic signal,

251 although the distribution of total $n$-alkanoic acids do show some phylogenetic structure $(\mathrm{K}=0.62, p=$

252 0.01). This appears to be due to the consistently higher total $n$-alkanoic acid concentrations in the

253 Pinaceae clade, which imparts a weak phylogenetic structure to the data. It is also important to note here

254 that $n$-alkanoic acids are indeed present, especially in Pinaceae $(105 \pm 89 \mu \mathrm{g} / \mathrm{g}, 1 \sigma, \mathrm{n}=10)$, but are

255 generally lower in concentration than in previously reported angiosperms $(335 \pm 294 \mu \mathrm{g} / \mathrm{g}, 1 \sigma, \mathrm{n}=29$,

256 Diefendorf et al., 2011). The $n$-alkanols have much lower concentrations in conifers studied here (99 \pm

$257252 \mu \mathrm{g} / \mathrm{g}, 1 \sigma, \mathrm{n}=43)$ than in angiosperms $(1167 \pm 1190 \mu \mathrm{g} / \mathrm{g}, 1 \sigma, \mathrm{n}=29$, Diefendorf et al., 2011).

259 The similar concentration of $n$-alkanoic acids in Pinaceae and angiosperms suggests that sediments will

260 contain leaf waxes from each group in rough proportion to their abundances. Since conifers and

261 angiosperms fractionate carbon differently during photosynthesis and biosynthesis, and have different

262 responses to water availability, this mixing will complicate interpretation of the isotopic composition of

$263 n$-alkanoic acids from sediments (Collister et al., 1994b; Chikaraishi and Naraoka, 2003; Bi et al., 2005; 
Vogts et al., 2009; Diefendorf et al., 2010; Polissar and Freeman, 2010; Diefendorf et al., 2011; Sachse et al., 2012; see Section 3.3 for further discussion).

\section{2. $n$-Alkane characteristics and phylogenetic relationships}

The $n$-alkanes are on average higher in concentration $\left(\mathrm{C}_{25}\right.$ to $\left.\mathrm{C}_{38} ; \bar{X}=173 \pm 193 \mu \mathrm{g} / \mathrm{g}, 1 \sigma, \mathrm{n}=43\right)$ than the $n$-alkanols and the $n$-alkanoic acids (Wilcoxon rank-sum test, $p<0.005$ ). This pattern extends to most

271 conifer families except for Pinaceae, which tends to have more $n$-alkanoic acids (Fig. 1). This pattern was 272 also observed in a previous study (Diefendorf et al., 2011). Interestingly, there is no correlation between $273 n$-alkane concentrations and $n$-alkanols or $n$-alkanoic acids, e.g., high concentrations of $n$-alkanes do not necessarily indicate high concentrations of $n$-alkanols or $n$-alkanoic acids. This may be attributed to the different functions of $n$-alkyl lipids and their relatives in controlling the physiochemical properties of leaf waxes, especially with respect to crystal structure, morphology, chemical behavior, plasticity, and permeability (Riederer and Schneider, 1990; Müller and Riederer, 2005; Jetter et al., 2006).

$n$-Alkane concentrations vary among the major conifer lineages (Fig. 1 and 3). For example, $n$-alkane concentrations are high in the Araucariaceae, Podocarpaceae, and Taxaceae, as well as the Callitroideae and Cupressoideae clades within Cupressaceae. In contrast, Pinaceae, Sciadopityaceae, and taxodioid

282 conifers (early diverging lineages of Cupressaceae) all have low concentrations. ACL and CPI also vary 283 among conifer clades, with the highest values in the Callitroideae and Cupressoideae (Fig. 3). Notably,

284 these two groups have much higher $n$-alkane concentrations, ACL values, and CPI values than do 285 representatives of early-diverging lineages within the Cupressaceae. Total $n$-alkane concentrations in

286 Podocarpaceae are similar to Callitroideae and Cupressoideae, but their composition is different; species 287 in Podocarpaceae tend to have much lower ACL values. 
A PCA of total $n$-alkanes $\left(\mathrm{C}_{25}\right.$ to $\left.\mathrm{C}_{38}\right)$, ACL, and CPI further indicates these variables are phylogenetically structured (Fig. 4a). Cupressoideae and Callitroideae species plot negatively on Principal Component

291 Axis 1 (PC 1), which summarizes $66 \%$ of the variation in the data and is negatively correlated with all 292 three variables. Araucariaceae and Podocarpaceae show intermediate values on PC I, while Pinaceae and 293 many taxodioid Cupressaceae (although not all) plot more positively. Principal Component Axis 2, which 294 explains $16 \%$ of the variation in the data and is positively correlated with CPI and negatively correlated 295 with ACL, shows less obvious phylogenetic structure. Correcting for the phylogenetic non-independence 296 of the data when calculating principal components scores does not significantly change these results, 297 although in this case species show more variation on PC 2, with Cupressoideae and Callitroideae plotting 298 somewhat negatively compared to other conifers (Fig. 4b).

Direct tests of phylogenetic signal in these variables ( $n$-alkane concentration, ACL, CPI, and PC 1 scores) further supports the idea that evolutionary history influences their values. ACL, CPI, and PC 1 scores show significant phylogenetic signal, where the distribution of their values across conifers is consistent with expectations from a Brownian motion evolutionary process operating across the observed

304 phylogenetic relationships among the species (Table 1). Phylogenetic signal is particularly strong in ACL 305 and PC 1 (both in regular and phylogeny-adjusted values). In contrast, total $n$-alkane concentration does not show a statistically significant phylogenetic signal. Concentrations of individual $n$-alkanes likewise do 307 not generally show evidence of phylogenetic signal, except for $\mathrm{C}_{28}$ and $\mathrm{C}_{29}$ (Table 1).

309 Overall, the concentrations of $n$-alkanes in these conifers are significantly different from previous studies 310 that indicated that $n$-alkanes are 200 times higher in angiosperms than conifers (Diefendorf et al., 2011).

311 This prior study focused on North American conifer species only and did not include any representatives

312 from major lineages that grow today in the Southern Hemisphere (Araucariaceae, Callitroids,

313 Podocarpaceae) or from a number of Northern Hemisphere genera now restricted to Asia but formerly

314 more widespread (e.g., Cunninghamia, Keteleeria, Pseudolarix). Representatives from these genera and 
315 families were components of North American floras at various times in the past; for example,

316 Araucariaceae is found in North America and Europe until the end-Cretaceous (Kunzmann, 2007; Stults

317 et al., 2012) and Cunninghamia was present until at least the Middle Miocene (Otto et al., 2003). This

318 study confirms that Pinaceae and taxodioid Cupressaceae have significantly lower concentrations of $n$ -

319 alkanes compared to angiosperms, as was concluded by Diefendorf et al. (2011). However, many conifer

320 taxa do indeed produce significant concentrations of $n$-alkanes. This has important implications for

321 interpreting sedimentary leaf waxes and their carbon and hydrogen isotopes in locations where

322 Cupressoideae, Callitroideae, Araucariaceae and Podocarpaceae are common today or were common in

323 the past.

325 Previous leaf wax studies have indicated that leaf lifespan appears to be an important control on leaf 326 waxes and that longer-lived leaves tend to have greater concentrations (Diefendorf et al., 2011). In this 327 study, seasonally deciduous species tend to plot higher on PC Axis 1 (Fig. 5a), which is associated with 328 fewer total alkanes, lower ACL, and lower CPI. The small number of deciduous conifers makes the 329 significance of these patterns difficult to interpret, however; evergreen species show a greater average 330 concentration of $n$-alkanes than deciduous species (Fig. 5b), but this difference is not statistically 331 significant ( $p=0.10$ with Mann-Whitney U-test). When examined within a proper phylogenetic context, 332 these differences become even less pronounced. Deciduous conifers are found only in the Pinaceae clade 333 (Larix, Pseudolarix) and among the early-diverging taxodioid Cupressaceae lineages (Glyptostrobus, 334 Metasequoia, Taxodium). When these deciduous species are compared to related evergreen taxa from 335 their respective groups, they do not have lower $n$-alkane concentrations (Fig. 5b). In fact, deciduous 336 taxodioid species have higher average $n$-alkane concentrations than evergreen taxodioid species, although 337 this difference is not significant ( $p=0.55$ with Mann-Whitney U-test). The higher average $n$-alkane 338 concentrations of evergreen conifers as a whole is essentially an artifact of sampling; it is due to the 339 abundance of Cupressoideae, Callitroideae, and Podocarpaceae species that are uniformly evergreen and 340 have clade-specific high $n$-alkane concentrations. Leaf life span in conifers ranges from $<1$ year to many 
decades (e.g., Niinemets and Lukjanova, 2003), and $n$-alkane concentrations have so far only been contrasted between deciduous and "evergreen" species, leaving more refined analyses for the future.

344 All of the samples collected in this study were grown at the same site and thus the same climate, although variations in water availability across the site cannot be ruled out (UCBGB occasionally waters plants, pers. comm.). Nonetheless, the strong phylogenetic clustering in the $n$-alkanes suggests that climate alone

347 may not be the primary factor influencing $n$-alkane biochemistry at the time of synthesis, at least at the

348 broadest scale. For example, Cupressaceae species differ dramatically in their physiology and the types of 349 environments they inhabit, from drought adapted species living in arid regions to drought intolerant 350 species living in wet habitats ((Pittermann et al., 2012; Brodribb et al., 2014), but our data suggests all 351 species have relatively high ACL values that they appear to have inherited from a common ancestor (Fig. 3522 and 3). A possible implication of our data, then, is that $n$-alkane chemistry and ACL values do not have any strong functional or adaptive significance, and major differences among clades simply reflect drift over hundreds of millions of years of independent evolution. On the other hand, some studies suggest that alkane chemistry does play a functional role; for example, longer chain waxes may act as protection against water loss within Cupressaceae species (Dodd et al., 1998; Dodd and Poveda, 2003). One way to

357 reconcile these results could be that phylogenetic relationships broadly structure patterns of $n$-alkane 358 chemistry regardless of climate, but climate or other environmental effects still plays a role in determining specific ACL values within or among species. Our results do strongly suggest, however, that searching

360 for such influences has to be done in a phylogenetic context.

362 Regardless of the exact relationship between climate and ACL, which has been investigated in a number 363 of studies (Dodd et al., 1998; Hoffmann et al., 2013; Tipple and Pagani, 2013; Bush and McInerney, 364 2015), one implication of our results is that interpreting alkane data, such as ACL values, from the fossil 365 record may be complicated by changes in species composition. For example, the Eocene Thunder 366 Mountain Flora (Erwin and Schorn, 2005) and the Oligocene Creede Flora (Axelrod, 1987; Wolfe and 
Schorn, 1990) both record upland environments with abundant conifers, but the latter is dominated by a single species of Juniperus while the former is predominantly Pinaceae. Regardless of whatever actual climatic differences may have existed between these floras, their ACL and CPI values are likely to be

370 affected by differences in species composition alone, in this case the high ACL and CPI values of

371 Cupressaceae relative to Pinaceae. Of course, differences in species composition are also likely to be

372 associated with differences in moisture or temperature regimes, but our results suggest that the

373 phylogenetic relationships alone are important to consider when interpreting $n$-alkane chain lengths.

\subsection{Carbon isotope fractionation during $n$-alkane biosynthesis}

Fractionation during decarboxylation of pyruvate discriminates against ${ }^{13} \mathrm{C}$ and results in acetyl-CoA being 4.5\%o lower than bulk tissue (Park and Epstein, 1961; Monson and Hayes, 1982; Melzer and Schmidt, 1987). Previous studies focusing on $n$-alkanes have measured $n$ - $\mathrm{C}_{29} \varepsilon_{\text {alkane }}$ values of $-4.4 \pm 2.3 \%$ o $(1 \sigma, n=3)$ for conifers and angiosperms grown at a single location in Pennsylvania (Diefendorf et al., 2011) and other studies have found similar results for different combinations of species (Collister et al., 1994b; Chikaraishi and Naraoka, 2003; Chikaraishi et al., 2004; Bi et al., 2005). In this study, we find conifers have $n-\mathrm{C}_{29} \varepsilon_{\text {alkane }}$ values of $-4.1 \pm 3.1(1 \sigma, \mathrm{n}=24)$ and $\varepsilon_{n \text {-alkane weighted }}$ values of $-3.9 \pm 2.5(1 \sigma, \mathrm{n}=$ 41). These results are similar to prior studies and also suggests that fractionation occurs primarily during decarboxylation of pyruvate.

Interestingly, $\varepsilon_{n \text {-alkanes-weighted }}$ values are distinct among major conifer groups, with the highest values in Pinaceae and the lowest values in Taxaceae (Fig. 6; ANOVA, $\mathrm{R}^{2}=0.65, p<0.001$ ). We also observed a

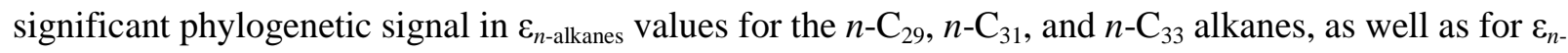


Positive linear correlations have been observed between total amount of leaf lipids and enrichment factors

394 (Park and Epstein, 1961; Hobbie and Werner, 2004). However, we do not observe this relationship

395 between $\varepsilon_{n \text {-alkane }}$ and total $n$-alkanes or total $n$-alkyl lipids in this study. Also, individual $n$-alkane chain

396 length concentrations and $\varepsilon_{n \text {-alkane }}$ values are not correlated, even within an individual family. For example,

397 the subfamilies within Cupressaceae have similar $\varepsilon_{n \text {-alkanes }}$ values, but a large range in $n$-alkane

398 concentrations. We speculate that a correlation is not observed because $n$-alkanes represent a small

399 portion of the total leaf lipid pool and are not continuously produced (e.g., Tipple et al., 2013). Thus,

400 enzymatic isotope effects between reactant and product are not clearly related to lipid production flux as

401 is observed in the total lipid pool (Park and Epstein, 1961; Hayes, 2001).

402

403 Although, on average, the $\varepsilon_{n \text {-alkanes weighted }}$ values are close to $-4.5 \%$ (Park and Epstein, 1961; Monson and

404 Hayes, 1982; Melzer and Schmidt, 1987), several species in Pinaceae are more than $1 \sigma$ above the mean, and Taxaceae, Podocarpaceae, and one species in Araucariaceae are more than $1 \sigma$ below (Fig. 6). Some of this variability in $\varepsilon_{n \text {-alkanes weighted }}$ values could be caused by phenological differences among species. If

407 leaf waxes and bulk leaf tissue are not synthesized at the same time, species that produce new growth at

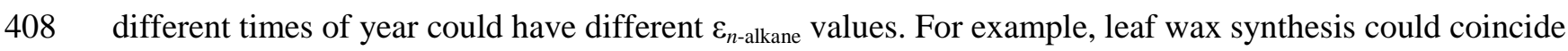
409 with periods of either high or low photosynthetic demand or water availability. This directly translates 410 into a control on pyruvate $\delta^{13} \mathrm{C}$ values with high values during periods of greatest photosynthetic demand 411 and/or decreased water availability (Farquhar et al., 1989; Diefendorf et al., 2010). Alternatively, carbon 412 metabolism could be different among species such that the source of pyruvate utilized in the acetogenic 413 pathway varies (Zhou et al., 2010) or the timing of synthesis varies. For example, if a large percentage of 414 leaf waxes are synthesized during bud break and leaf flush, as suggested by Tipple et al. (2013), then leaf 415 wax $\delta^{13} \mathrm{C}$ may ultimately be controlled by the proportion of stored sugars utilized to produce pyruvate and 416 thus cause ${ }^{13} \mathrm{C}$ enrichment (Terwilliger and Huang, 1996; Jäggi et al., 2002), as has been suggested for 417 non-photosynthetic tissues (Cernusak et al., 2009). On the other hand, if leaf wax synthesis occurs 
throughout the growing season (Sachse et al., 2006; Sachse et al., 2009), then stored sugars could be less

419 important as source of pyruvate. Differences in carbon metabolism therefore could be an important factor

420 controlling variations in $\varepsilon_{n \text {-alkanes. }}$

422 Different species of plants produce different amounts of various $n$-alkane chain lengths, and that the 423 isotopic composition of these chain lengths is affected both by taxon-specific biosynthetic fractionation

424 factors and common environmental effects that influence photosynthetic fractionation. In order to extract 425 an environmental signal from sedimentary leaf waxes, it then becomes necessary to know the proportion 426 of the wax in the sample that comes from the different taxa. For example, if the conifers in a mixed 427 conifer/angiosperm forest are Juniperus or Thuja, then interpreting the $\delta^{13} \mathrm{C}$ of $n-\mathrm{C}_{29}$ alkane as an 428 angiosperm biomarker would be justified; Juniperus and Thuja produce almost entirely $n$-alkanes longer 429 than $\mathrm{C}_{31}$. Interpreting sedimentary $n$-alkanes in mixed forests of angiosperms and Podocarpaceae will be 430 challenging given that both produce abundant $n-\mathrm{C}_{29}$ alkanes. Plant communities with grasses and 431 Callitroideae and/or Cupressoideae will be more problematic given the predominance of grasses with 432 chain lengths longer than $n-\mathrm{C}_{31}$ and thus overlapping in chain length with these conifer subfamilies. 433 Choosing the correct $n$-alkane chain length for interpreting isotope signals will be critical and must be 434 constrained with independent information about vegetation.

\section{CONCLUSIONS}

438 We provide new measurements of leaf wax composition and $\varepsilon_{n \text {-alkanes }}$ values for 43 conifer species (and

439 Ginkgo biloba) from the University of California Botanical Garden at Berkeley. This sampling provides

440 information at the same site, thereby minimizing effects of climate, for all extant conifer families and

441 most extant genera. We find that $n$-alkanes are indeed common in many conifer families, especially

442 families that are common today in the Southern Hemisphere and Asia, including Araucariaceae,

443 Podocarpaceae, and many species of Cupressaceae, especially in the subfamilies Cupressoideae and 
444 Callitroideae. Pinaceae, Sciadopityaceae, and the early diverging taxodioid lineage within Cupressaceae, 445 however, are characterized by low concentrations of $n$-alkanes.

447 The concentration and chain length of $n$-alkanes both are strongly influenced by evolutionary history; a

448 strong phylogenetic signal is present in the $n-\mathrm{C}_{29}$ alkane concentrations, average chain length, and carbon

449 preference index. The role of the environment in shaping $n$-alkane composition is, however, unclear.

450 Average chain length significantly varies among conifer families and strongly indicates that species

451 composition will have a critical control on average chain length in sedimentary archives, thus

452 interpretations of average chain length as a proxy for climate must be done cautiously and with careful

453 regard for phylogenetic context.

455 We found that the values of $n-\mathrm{C}_{29} \varepsilon_{\text {alkane }}$ and $\varepsilon_{n \text {-alkane weighted }}$ in conifers to be broadly consistent with

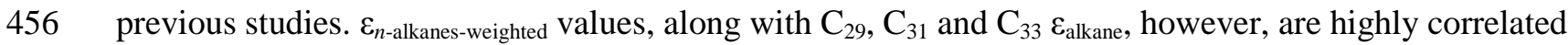
457 with phylogenetic relationships among conifers. This suggests that biosynthetic fractionation may be 458 related to differences in carbon allocation or metabolism among conifer groups, although the exact 459 mechanism is unknown and will require further research.

461 Overall, our findings show that some conifers have the potential to make major contributions to $n$-alkanes 462 in sediments. The possibility that such conifers have contributed to the $n$-alkanes in any given sediment 463 sample will have to be determined from other sources of information, such as pollen and/or macrofossils.

464 If $n$-alkane producing conifers are present, it may still be possible to separate angiosperm from conifer 465 biomarkers by selecting a particular $n$-alkane chain length that is produced mostly by either angiosperms 466 or conifers. This is particularly important in the context of interpreting the $\delta^{13} \mathrm{C}$ of $n$-alkanes because 467 conifers and angiosperms fractionate differently during photosynthesis (e.g. Diefendorf et al., 2010).

468 Mixing of conifer and angiosperm derived $n$-alkanes could cause variation in sedimentary $\delta^{13} \mathrm{C}_{\text {alkane }}$ values 
469 that could be misinterpreted as change in the $\delta^{13} \mathrm{C}$ of the carbon cycle, changes in vegetation, or changes

470 in water use efficiency.

471

472 ACKNOWLEDGEMENTS

473

474 We thank Holly Forbes and the staff at the University of California Botanical Garden at Berkeley for

475 access to specimens and assistance with sample collection. We thank Cindy Looy for assistance with

476 sample collection for earlier preliminary sampling not used in this study. We also thank Justin Dodd and

477 Kevin Mueller for assistance with sampling. Sharmila Giri, Douglas Sberna, Keegan McClannahan, Brian

478 Simpkins, and Katherine Finan are thanked for assistance with sample preparation. We also thank Jeremy

479 Beaulieu and Elisabeth Forrestel for their support with data analysis methods. This research was

480 supported by the National Science Foundation (EAR-1229114 to A.F.D.) and the American Chemical

481 Society Petroleum Research Fund (PRF \#51787-DNI2 to A.F.D.).

482

483

484

485

486

\section{APPENDIX A. SUPPLEMENTARY DATA}

Supplementary data associated with this article can be found, in the online version, at insert DOI link. 


\section{Figure Captions}

Figure 1. The average $n$-alkane $\left(\mathrm{C}_{25}\right.$ to $\left.\mathrm{C}_{38}\right), n$-alkanol (even chains from $\mathrm{C}_{24}$ to $\mathrm{C}_{34}$ ), and $n$-alkanoic acid (even chains from $\mathrm{C}_{24}$ to $\mathrm{C}_{30}$ ) concentrations for each of the major conifer groups. Concentrations are reported in $\mu \mathrm{g} / \mathrm{g}$ dry leaf material with one standard error indicated.

Figure 2. $n$-Alkane concentrations for the 43 conifer species and Ginkgo biloba. Conifer species are grouped into major clades with a DNA sequenced-based phylogeny that is age-calibrated using the fossil record (Rai et al., 2008; Leslie et al., 2012). The $n$-alkane concentrations ( $\mu \mathrm{g} / \mathrm{g}$ dry leaf material) are reported for odd $n$-alkanes from $\mathrm{C}_{25}$ to $\mathrm{C}_{37}$.

Figure 3. Carbon preference index (CPI) and average chain length (ACL) for major conifer groups. Box and whisker plots show the median, upper and lower quartiles, and maximum and minimum values, with outliers shown. Each black dot represents one species.

Figure 4. A) Principle components analysis (PCA) of $n$-alkanes concentrations, ACL, and CPI for all species. B) Phylogenetically corrected PCA that accounts for the phylogenetic non-independence of the data.

Figure 5. A) The phylogenetically corrected PCA from Fig. 4 with leaf lifespan indicated. B) Total $n$ alkane concentrations ( $\mu \mathrm{g} / \mathrm{g}$ dry leaf, $\log$ scale) for all conifers, Pinaceae and taxodioid Cupressaceae with leaf lifespan indicated (E, evergreen; D, deciduous). See Figure 3 caption for description of box and whiskers plots.

Figure 6. Fractionation during $n$-alkane biosynthesis weighted by $n$-alkane concentration ( $\left.\varepsilon_{n \text {-alkane weighted }}\right)$.

Black dots represent one species and box and whisker plots represent the median, upper and lower quartiles, and maximum and minimum values for each major conifer group. For reference, the mean, 
514 upper and lower quartiles, and upper and lower 1 standard deviation about the mean are shown for all 515 conifers.

516 


\section{References}

Axelrod, D.I. (1987) The late Oligocene Creede flora, Colorado. Univ. Calif. Pub. Geol. Sci. 130, 180198.

Bi, X., Sheng, G., Liu, X., Li, C. and Fu, J. (2005) Molecular and carbon and hydrogen isotopic composition of $n$-alkanes in plant leaf waxes. Org. Geochem. 36, 1405-1417.

Blomberg, S.P., Garland, T., Ives, A.R. and Crespi, B. (2003) Testing for phylogenetic signal in comparative data: Behanioral traits are more labile. Evolution 57, 717-745.

Brodribb, T.J., McAdam, S.A.M., Jordan, G.J. and Martins, S.C.V. (2014) Conifer species adapt to lowrainfall climates by following one of two divergent pathways. Proc. Natl. Acad. Sci. U.S.A. 111, 1448914493.

Bush, R.T. and McInerney, F.A. (2013) Leaf wax $n$-alkane distributions in and across modern plants: Implications for paleoecology and chemotaxonomy. Geochim. Cosmochim. Acta 117, 161-179. Bush, R.T. and McInerney, F.A. (2015) Influence of temperature and C4 abundance on $n$-alkane chain length distributions across the central USA. Org. Geochem. 79, 65-73.

Castañeda, I.S. and Schouten, S. (2011) A review of molecular organic proxies for examining modern and ancient lacustrine environments. Quat. Sci. Rev. 30, 2851-2891.

Castañeda, I.S., Werne, J.P., Johnson, T.C. and Filley, T.R. (2009) Late Quaternary vegetation history of southeast Africa: The molecular isotopic record from Lake Malawi. Palaeogeogr. Palaeocl. Palaeoecol. $275,100-112$.

Cernusak, L.A., Tcherkez, G., Keitel, C., Cornwell, W.K., Santiago, L.S., Knohl, A., Barbour, M.M., Williams, D.G., Reich, P.B., Ellsworth, D.S., Dawson, T.E., Griffiths, H.G., Farquhar, G.D. and Wright, I.J. (2009) Why are non-photosynthetic tissues generally ${ }^{13} \mathrm{C}$ enriched compared with leaves in C3 plants? Review and synthesis of current hypotheses. Func. Plant Bio. 36, 199-213.

Chikaraishi, Y. and Naraoka, H. (2003) Compound-specific $\delta$ D- $\delta{ }^{13} \mathrm{C}$ analyses of $n$-alkanes extracted from terrestrial and aquatic plants. Phytochemistry 63, 361-371. 
543 Chikaraishi, Y., Naraoka, H. and Poulson, S.R. (2004) Hydrogen and carbon isotopic fractionations of

544 lipid biosynthesis among terrestrial (C3, C4 and CAM) and aquatic plants. Phytochemistry 65, 1369-

5451381.

546 Collister, J.W., Lichtfouse, E., Hieshima, G. and Hayes, J.M. (1994a) Partial resolution of sources of n-

547 alkanes in the saline portion of the Parachute Creek Member, Green River Formation (Piceance Creek

548 Basin, Colorado). Org. Geochem. 21, 645-659.

549 Collister, J.W., Rieley, G., Stern, B., Eglinton, G. and Fry, B. (1994b) Compound-specific $\delta{ }^{13}$ C analyses

550 of leaf lipids from plants with differing carbon dioxide metabolisms. Org. Geochem. 21, 619-627.

551 Coplen, T.B., Brand, W.A., Gehre, M., Gröning, M., Meijer, H.A.J., Toman, B. and Verkouteren, R.M.

552 (2006) New guidelines for $\delta{ }^{13} \mathrm{C}$ measurements. Anal. Chem. 78, 2439-2441.

553 Cranwell, P.A. (1981) Diagenesis of free and bound lipids in terrestrial detritus deposited in a lacustrine

554 sediment. 3, 79-89.

555 Diefendorf, A.F., Freeman, K.H., Wing, S.L. and Graham, H.V. (2011) Production of $n$-alkyl lipids in

556 living plants and implications for the geologic past. Geochim. Cosmochim. Acta 75, 7472-7485.

557 Diefendorf, A.F., Mueller, K.E., Wing, S.L., Koch, P.L. and Freeman, K.H. (2010) Global patterns in leaf

$558{ }^{13} \mathrm{C}$ discrimination and implications for studies of past and future climate. Proc. Natl. Acad. Sci. U.S.A. $559 \quad 107,5738-5743$.

560 Dodd, M.B., Lauenroth, W.K. and Welker, J.M. (1998) Differential water resource use by herbaceous and 561 woody plant life-forms in a shortgrass steppe community. Oecologia 117, 504-512.

562 Dodd, R.S. and Poveda, M.M. (2003) Environmental gradients and population divergence contribute to 563 variation in cuticular wax composition in Juniperus communis. Biochem. Syst. Ecol. 31, 1257-1270.

564 Douglas, P.M.J., Pagani, M., Brenner, M., Hodell, D.A. and Curtis, J.H. (2012) Aridity and vegetation 565 composition are important determinants of leaf-wax $\delta \mathrm{D}$ values in southeastern Mexico and Central 566 America. Geochim. Cosmochim. Acta 97, 24-45. 

wax coatings of plant leaves: A taxonomic survey. Phytochemistry 1, 89-102.

569 Eglinton, G. and Hamilton, R.J. (1967) Leaf epicuticular waxes. Science 156, 1322-1335.

570 Erwin, D.M. and Schorn, H.E. (2005) Revision of the conifers from the Eocene Thunder Mountain flora, 571 Idaho, USA. Rev. Palaeobot. Palynology 137, 125-145.

572 Farquhar, G.D., Ehleringer, J.R. and Hubick, K.T. (1989) Carbon isotope discrimination and

573 photosynthesis. Annu. Rev. Plant Phys. Plant Biol. 40, 503-537.

574 Feakins, S.J., Eglinton, T.I. and deMenocal, P.B. (2007) A comparison of biomarker records of northeast 575 African vegetation from lacustrine and marine sediments (ca. 3.40 Ma). Org. Geochem. 38, 1607-1624.

576 Freeman, K.H. and Colarusso, L.A. (2001) Molecular and isotopic records of C4 grassland expansion in 577 the late Miocene. Geochim. Cosmochim. Acta 65, 1439-1454.

578 Freeman, K.H. and Pancost, R.D. (2014) Biomarkers for Terrestrial Plants and Climate, in: Turekian, 579 H.D., Holland, K.K. (Eds.), Treatise on Geochemistry (Second Edition). Elsevier, Oxford, pp. 395-416.

580 Hayes, J.M. (2001) Fractionation of carbon and hydrogen isotopes in biosynthetic processes. Rev.

$581 \quad$ Mineral Geochem. 43, 225-277.

582 Hobbie, E.A. and Werner, R.A. (2004) Intramolecular, compound-specific, and bulk carbon isotope 583 patterns in C3 and C4 plants: a review and synthesis. New Phytol. 161, 371-385.

584 Hoffmann, B., Kahmen, A., Cernusak, L.A., Arndt, S.K. and Sachse, D. (2013) Abundance and 585 distribution of leaf wax $n$-alkanes in leaves of Acacia and Eucalyptus trees along a strong humidity 586 gradient in northern Australia. Org. Geochem. 62, 62-67.

587 Jäggi, M., Saurer, M., Fuhrer, J. and Siegwolf, R. (2002) The relationship between the stable carbon 588 isotope composition of needle bulk material, starch, and tree rings in Picea abies. Oecologia 131, 325589332.

590 Jetter, R., Kunst, L. and Samuels, A.L. (2006) Composition of plant cuticular waxes, in: Rieder, M., 591 Muller, C. (Eds.), Biology of the plant cuticle. Blackwell Publishing, Oxford, pp. 145-181. 
592 Kolattukudy, P., Croteau, R. and Buckner, J. (1976) Biochemistry of plant waxes, in: Kolattukudy, P.

593 (Ed.), Chemistry and Biochemistry of Natural Waxes. Elsevier, Amsterdam, pp. 289-347.

594 Kunzmann, L. (2007) Araucariaceae (Pinopsida): aspects in palaeobiogeography and palaeobiodiversity

595 in the Mesozoic. Zoo. Anz. - J. Comp. Zoo 246, 257-277.

596 Leslie, A.B., Beaulieu, J.M., Rai, H.S., Crane, P.R., Donoghue, M.J. and Mathews, S. (2012)

597 Hemisphere-scale differences in conifer evolutionary dynamics. Proc. Natl. Acad. Sci. U.S.A. 109,

$598 \quad 16217-16221$.

599 Melzer, E. and Schmidt, H. (1987) Carbon isotope effects on the pyruvate dehydrogenase reaction and

600 their importance for relative carbon-13 depletion in lipids. J. Biol. Chem. 262, 8159-8164.

601 Monson, K.D. and Hayes, J.M. (1982) Carbon isotopic fractionation in the biosynthesis of bacterial fatty

602 acids. Ozonolysis of unsaturated fatty acids as a means of determining the intramolecular distribution of

603 carbon isotopes. Geochim. Cosmochim. Acta 46, 139-149.

604 Mueller, K.E., Polissar, P.J., Oleksyn, J. and Freeman, K.H. (2012) Differentiating temperate tree species

605 and their organs using lipid biomarkers in leaves, roots and soil. Org. Geochem. 52, 130-141.

606 Müller, C. and Riederer, M. (2005) Plant surface properties in chemical ecology. J. Chem. Ecol. 31, 2621-

6072651.

608 Niedermeyer, E.M., Sessions, A.L., Feakins, S.J. and Mohtadi, M. (2014) Hydroclimate of the western

609 Indo-Pacific Warm Pool during the past 24,000 years. Proc. Natl. Acad. Sci. U.S.A. 111, 9402-9406.

610 Niinemets, Ü. and Lukjanova, A. (2003) Total foliar area and average leaf age may be more strongly

611 associated with branching frequency than with leaf longevity in temperate conifers. New Phytol. 158, 75-

61289.

613 Otto, A., Simoneit, B.R.T. and Rember, W.C. (2003) Resin compounds from the seed cones of three

614 fossil conifer species from the Miocene Clarkia flora, Emerald Creek, Idaho, USA, and from related

615 extant species. Rev. Palaeobot. Palynology 126, 225-241. 
617 Dickens, G.R. and the Expedition 302 Scientists (2006) Arctic hydrology during global warming at the

618 Palaeocene/Eocene thermal maximum. Nature 442, 671-675.

619 Park, R. and Epstein, S. (1961) Metabolic fractionation of C13 and C12 in plants. Plant Physiol. 36, 133-

620138.

621 Pittermann, J., Stuart, S.A., Dawson, T.E. and Moreau, A. (2012) Cenozoic climate change shaped the 622 evolutionary ecophysiology of the Cupressaceae conifers. Proc. Natl. Acad. Sci. U.S.A. 109, 9647-9652.

623 Polissar, P.J. and Freeman, K.H. (2010) Effects of aridity and vegetation on plant-wax $\delta$ D in modern

624 lake sediments. Geochim. Cosmochim. Acta 74, 5785-5797.

625 PRISM (2014) PRISM Climate Group, Oregon State University, http://prism.oregonstate.edu.

626 Rai, H.S., Reeves, P.A., Peakall, R., Olmstead, R.G. and Graham, S.W. (2008) Inference of higher-order

627 conifer relationships from a multi-locus plastid data set. Botany 86, 658-669.

628 Revell, L.J. (2009) Size-correction and principal components for interspecific comparative studies.

629 Evolution 63, 3258-3268.

630 Revell, L.J. (2012) Phytools: an R package for phylogenetic comparative biology (and other things).

631 Methods Ecol. Evol. 3, 217-223.

632 Riederer, M. and Schneider, G. (1990) The effect of the environment on the permeability and composition 633 of Citrus leaf cuticles. Planta 180, 154-165.

634 Rieley, G., Collier, R.J., Jones, D.M., Eglinton, G., Eakin, P.A. and Fallick, A.E. (1991) Sources of

635 sedimentary lipids deduced from stable carbon isotope analyses of individual compounds. Nature 352, $636 \quad 425-427$.

637 Sachse, D., Billault, I., Bowen, G.J., Chikaraishi, Y., Dawson, T.E., Feakins, S.J., Freeman, K.H., Magill, 638 C.R., McInerney, F.A., van der Meer, M.T.J., Polissar, P., Robins, R.J., Sachs, J.P., Schmidt, H.-L., 639 Sessions, A.L., White, J.W.C., West, J.B. and Kahmen, A. (2012) Molecular Paleohydrology: Interpreting 
640 the Hydrogen-Isotopic Composition of Lipid Biomarkers from Photosynthesizing Organisms. Annu. Rev.

641 Earth Planet. Sci. 40, 221-249.

642 Sachse, D., Kahmen, A. and Gleixner, G. (2009) Significant seasonal variation in the hydrogen isotopic

643 composition of leaf-wax lipids for two deciduous tree ecosystems (Fagus sylvativa and Acer

644 pseudoplatanus). Org. Geochem. 40, 732-742.

645 Sachse, D., Radke, J. and Gleixner, G. (2006) $\delta$ D values of individual $n$-alkanes from terrestrial plants

646 along a climatic gradient - Implications for the sedimentary biomarker record. Org. Geochem. 37, 469-

$647 \quad 483$.

648 Schouten, S., Woltering, M., Rijpstra, W.I.C., Sluijs, A., Brinkhuis, H. and Sinninghe Damste, J.S. (2007)

649 The Paleocene-Eocene carbon isotope excursion in higher plant organic matter: Differential fractionation

650 of angiosperms and conifers in the Arctic. Earth Planet. Sci. Lett. 258, 581-592.

651 Shepherd, T. and Wynne Griffiths, D. (2006) The effects of stress on plant cuticular waxes. New Phytol.

652 171, 469-499.

653 Smith, F.A., Wing, S.L. and Freeman, K.H. (2007) Magnitude of the carbon isotope excursion at the

654 Paleocene-Eocene thermal maximum: The role of plant community change. Earth Planet. Sci. Lett. 262,

$655 \quad 50-65$.

656 Stults, D.Z., Axsmith, B.J., Knight, T.K. and Bingham, P.S. (2012) The conifer Araucaria bladenensis

657 and associated large pollen and ovulate cones from the Upper Cretaceous Ingersoll shale (Eutaw

658 Formation) of Alabama. Cretac. Res. 34, 142-148.

659 Terwilliger, V.J. and Huang, J. (1996) Heterotrophic whole plant tissues show more ${ }^{13} \mathrm{C}$ enrichment than

660 their carbon sources. Phytochemistry 43, 1183-1188.

661 Tierney, J.E., Russell, J.M., Huang, Y., Damsté, J.S.S., Hopmans, E.C. and Cohen, A.S. (2008) Northern

662 Hemisphere Controls on Tropical Southeast African Climate During the Past 60,000 Years. Science 322,

$663252-255$. 
664 Tipple, B.J., Berke, M.A., Doman, C.E., Khachaturyan, S. and Ehleringer, J.R. (2013) Leaf-wax n-

665 alkanes record the plant-water environment at leaf flush. Proc. Natl. Acad. Sci. U.S.A. 110, 2659-2664.

666 Tipple, B.J. and Pagani, M. (2013) Environmental control on eastern broadleaf forest species' leaf wax

667 distributions and D/H ratios. Geochim. Cosmochim. Acta 111, 64-77.

668 Tipple, B.J., Pagani, M., Krishnan, S., Dirghangi, S.S., Galeotti, S., Agnini, C., Giusberti, L. and Rio, D.

669 (2011) Coupled high-resolution marine and terrestrial records of carbon and hydrologic cycles variations

670 during the Paleocene-Eocene Thermal Maximum (PETM). Earth Planet. Sci. Lett. 311, 82-92.

671 Vogts, A., Moossen, H., Rommerskirchen, F. and Rullkötter, J. (2009) Distribution patterns and stable

672 carbon isotopic composition of alkanes and alkan-1-ols from plant waxes of African rain forest and

673 savanna C3 species. Org. Geochem. 40, 1037-1054.

674 Vogts, A., Schefuß, E., Badewien, T. and Rullkötter, J. (2012) n-Alkane parameters from a deep sea

675 sediment transect off southwest Africa reflect continental vegetation and climate conditions. Org.

676 Geochem. 47, 109-119.

677 Wolfe, J.A. and Schorn, H.E. (1990) Taxonomic revision of the Spermatopsida of the Oligocene Creede

678 flora, southern Colorado. U.S. Geol. Surv. Bull. 1923.

679 Zhou, Y., Grice, K., Stuart-Williams, H., Farquhar, G.D., Hocart, C.H., Lu, H. and Liu, W. (2010)

680 Biosynthetic origin of the saw-toothed profile in $\delta{ }^{13} \mathrm{C}$ and $\delta{ }^{2} \mathrm{H}$ of $n$-alkanes and systematic isotopic

681 differences between $n-$, iso- and anteiso-alkanes in leaf waxes of land plants. Phytochemistry 71, 388-

682403.

683 
Table 1. Phylogenetic signal in conifer alkane data.

\begin{tabular}{|c|c|c|}
\hline Category & Trait & Blomberg $K^{\mathrm{a}}$ \\
\hline \multirow{17}{*}{$\begin{array}{l}\text { Individual } \\
\text { n-Alkanes }\end{array}$} & $\mathrm{C}_{22}$ & 0.22 \\
\hline & $\mathrm{C}_{23}$ & 0.16 \\
\hline & $\mathrm{C}_{24}$ & 0.24 \\
\hline & $\mathrm{C}_{25}$ & 0.32 \\
\hline & $\mathrm{C}_{26}$ & 0.49 \\
\hline & $\mathrm{C}_{27}$ & 0.29 \\
\hline & $\mathrm{C}_{28}$ & $0.64 *$ \\
\hline & $\mathrm{C}_{29}$ & $0.66 *$ \\
\hline & $\mathrm{C}_{30}$ & 0.52 \\
\hline & $\mathrm{C}_{31}$ & 0.41 \\
\hline & $\mathrm{C}_{32}$ & 0.40 \\
\hline & $\mathrm{C}_{33}$ & 0.43 \\
\hline & $\mathrm{C}_{34}$ & 0.45 \\
\hline & $\mathrm{C}_{35}$ & 0.34 \\
\hline & $\mathrm{C}_{36}$ & 0.29 \\
\hline & $\mathrm{C}_{37}$ & 0.29 \\
\hline & $\mathrm{C}_{38}$ & 0.19 \\
\hline \multirow{5}{*}{$\begin{array}{l}n \text {-Alkane } \\
\text { Statistics }\end{array}$} & Total Alkanes & 0.41 \\
\hline & $\mathrm{ACL}$ & $1.03 * *$ \\
\hline & CPI & $0.67 * *$ \\
\hline & PC1 ${ }^{\mathrm{b}}$ & $0.84 * *$ \\
\hline & $\mathbf{P C 1}_{\text {phy }}{ }^{\mathrm{c}}$ & $0.85 * *$ \\
\hline \multirow{4}{*}{$\begin{array}{l}n \text {-Alkane } \\
\text { fractionation }\end{array}$} & $\varepsilon_{n \text {-alkane }} C_{29}$ & $0.94 * *$ \\
\hline & $\varepsilon_{n \text {-alkane }} \mathrm{C}_{31}$ & $0.81 * *$ \\
\hline & $\varepsilon_{n \text {-alkane }} \mathbf{C}_{33}$ & $0.77 * *$ \\
\hline & $\boldsymbol{\varepsilon}_{n \text {-alkane weighted }}$ & $0.91 * *$ \\
\hline
\end{tabular}

${ }^{\mathrm{a}} \mathrm{A} K$ value of 0.0 indicates that a trait shows no phylogenetic signal while a value of 1.0 indicates that a trait shows the expected distribution given the phylogeny and a Brownian motion model of trait evolution; values greater than 1.0 are also possible. Statistical significance is assessed by a randomization test and significant values are indicated in bold. ${ }^{b} \mathrm{PC} 1$ is the individual species scores on the first Principal Component Axis. ${ }^{\mathrm{c}}$ $\mathrm{PC}_{\mathrm{PHY}}$ is the individual species scores after accounting for phylogenetic nonindependence in the data. *indicates significance at $p<0.05$, ** indicates $p<0.01$. 


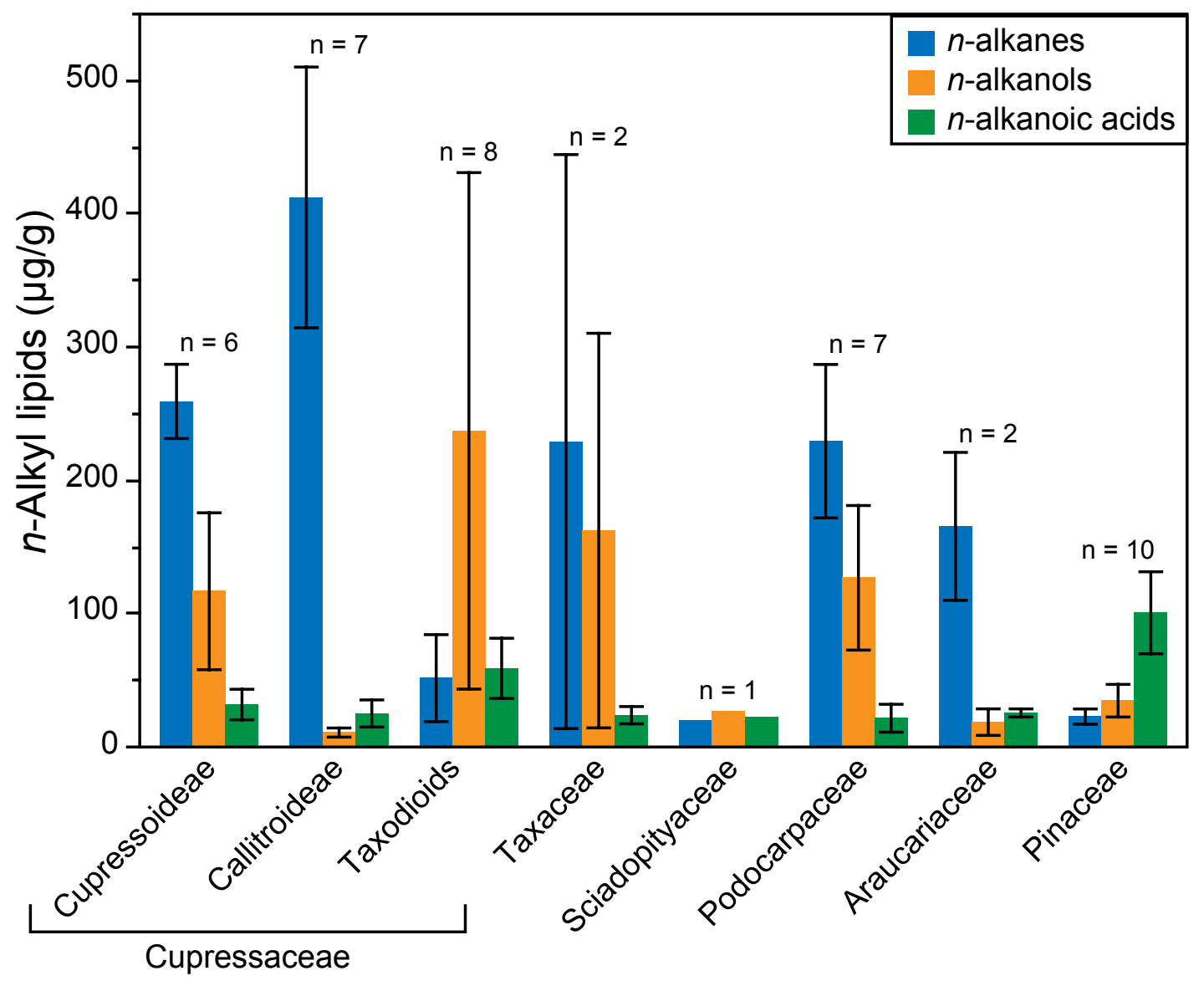




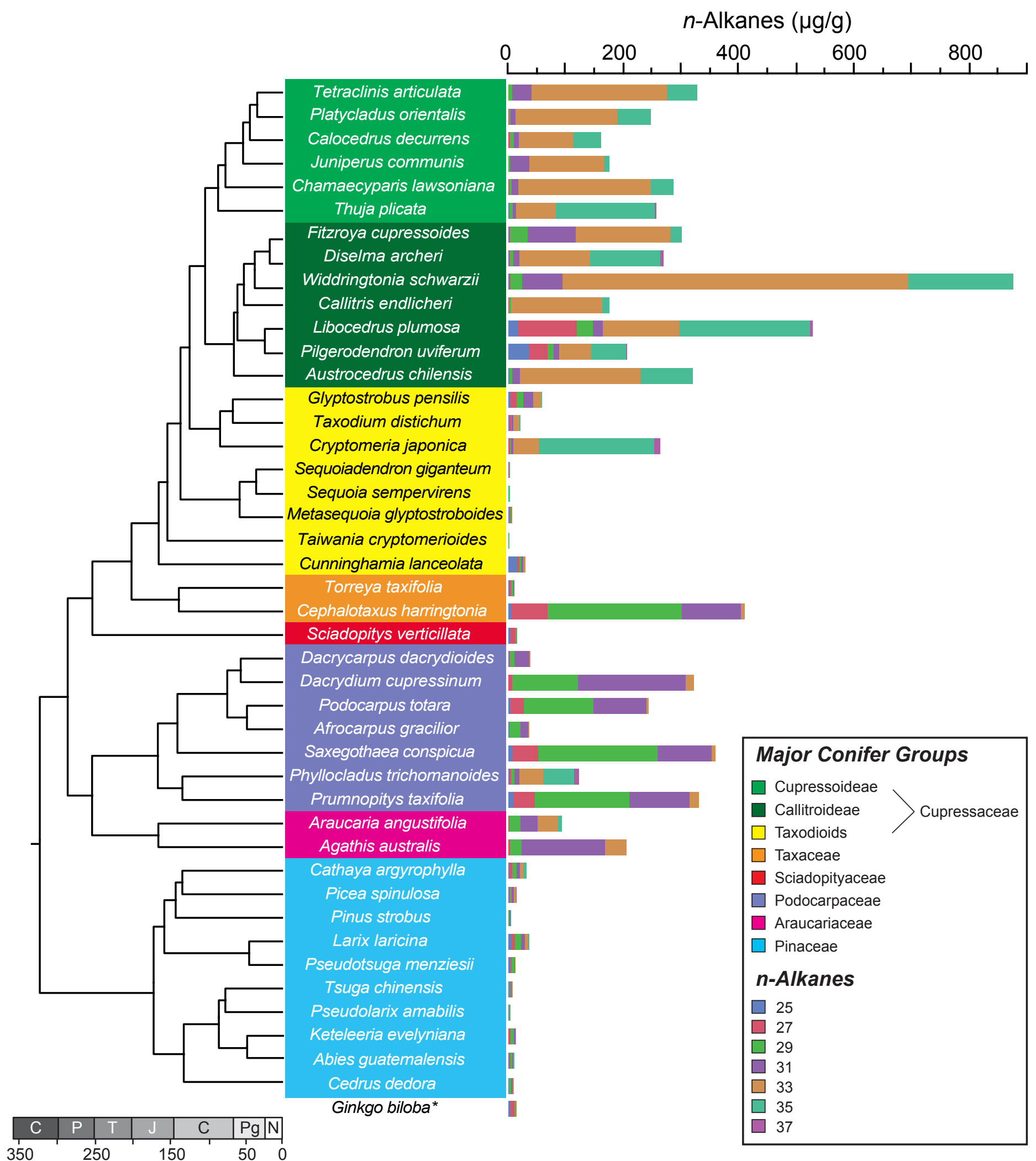

Major Conifer Groups
$\square$ Cupressoideae
$\square$ Callitroideae $>$ Cupressaceae
$\square$ Taxodioids
$\square$ Taxaceae
$\square$ Sciadopityaceae
$\square$ Podocarpaceae
$\square$ Araucariaceae
$\square$ Pinaceae
$\boldsymbol{n}$-Alkanes
$\square 25$
$\square 27$
$\square 29$
$\square 31$
$\square 33$
$\square 35$
$\square 37$




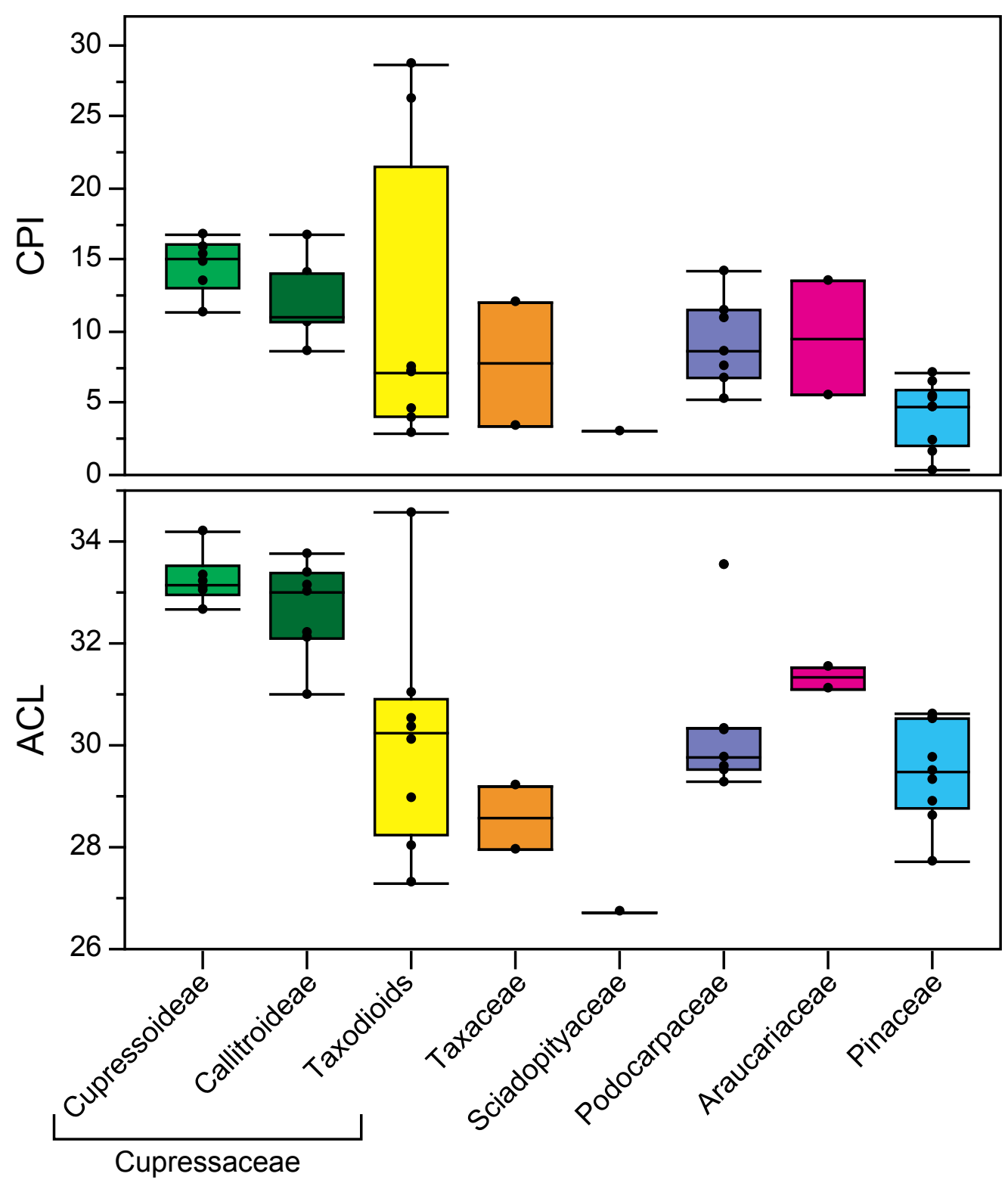


Figure 4

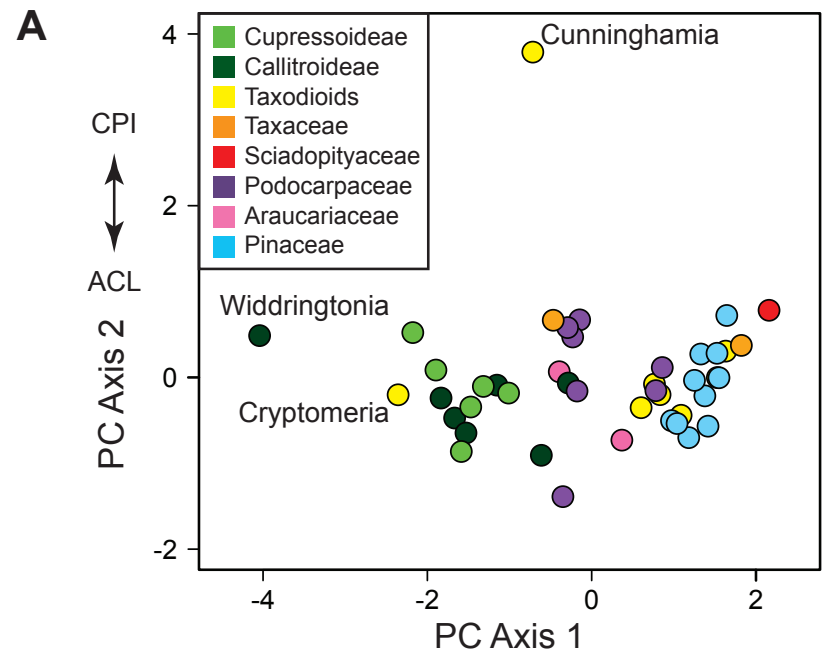

Total alkanes, ACL, CPI

CPI

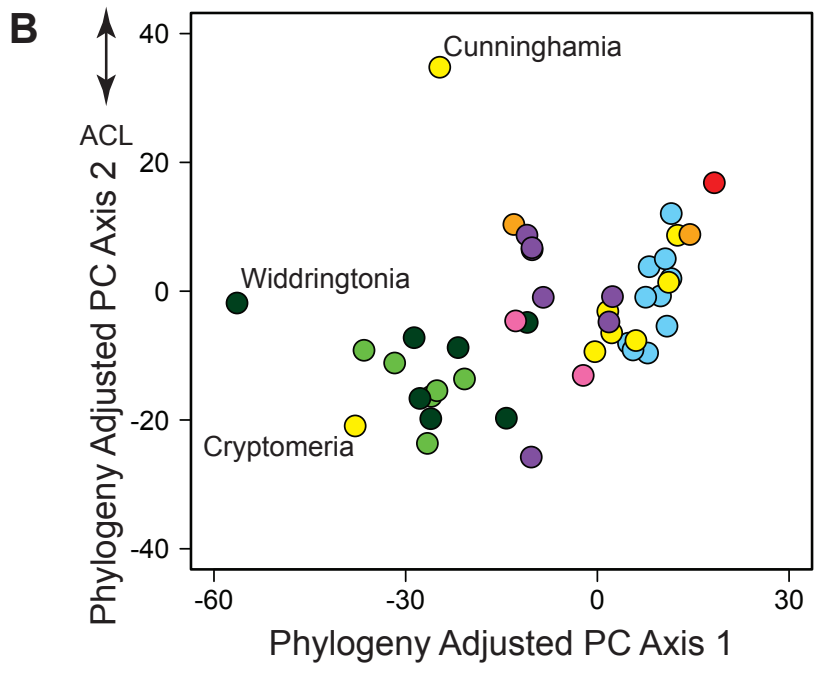

Total alkanes, ACL, CPI 
Figure 5

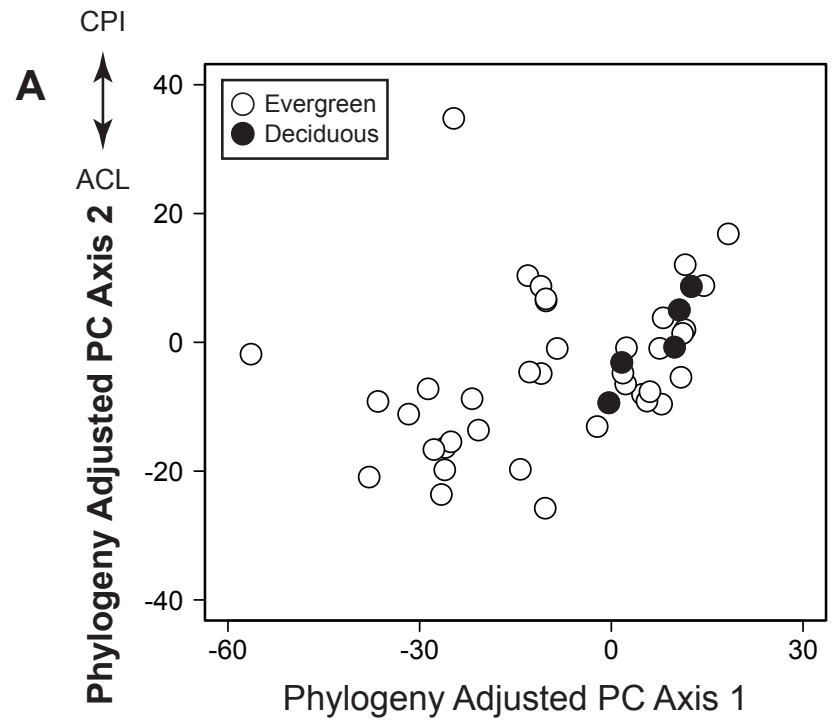

Total alkanes, ACL, CPI

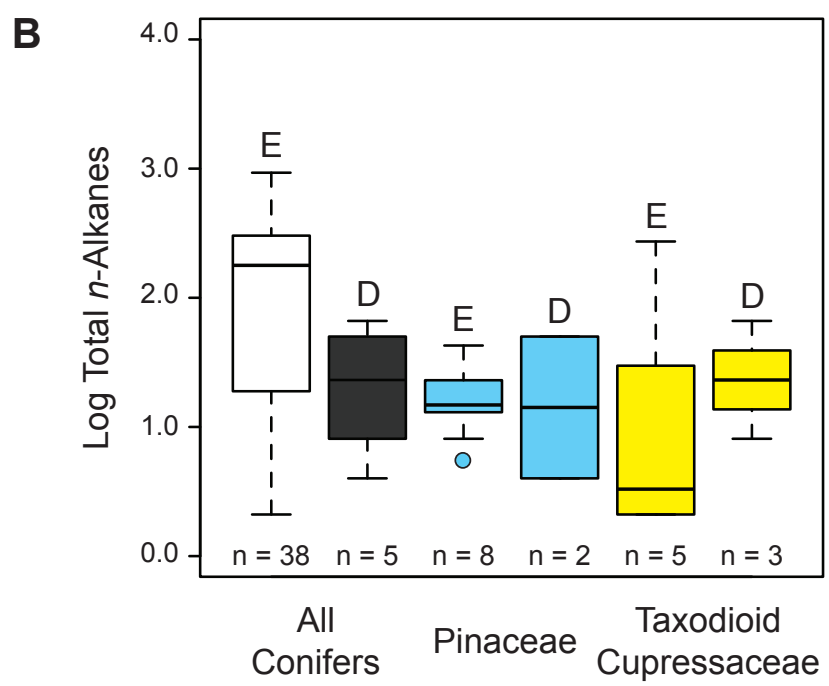


Figure 6

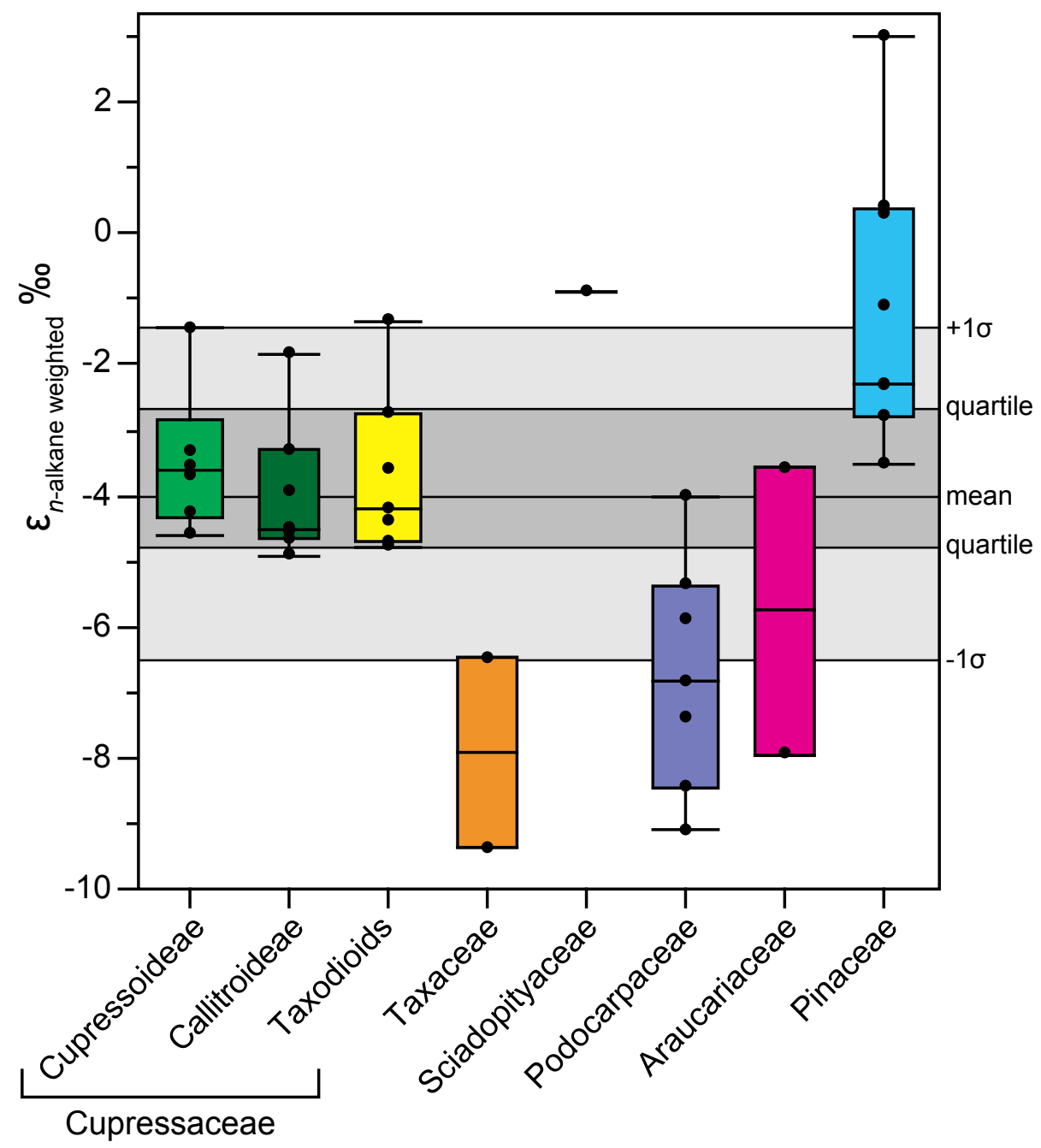

